
\title{
28 Research Suare \\ Relationship between Obesity and Eating Rate: Analyzing the Korean Community Health Survey Data
}

\section{Heui Sug Jo}

Kangwon National University School of Medicine

Su Mi Jung

Kangwon Public Policy Institute

Yuliya Dronina ( $\square$ julia_dronina@yahoo.com )

Kangwon National University School of Medicine https://orcid.org/0000-0002-5912-3553

\section{Research}

Keywords: Obesity, Eating rate, Dietary habits, Community Health Survey (CHS)

Posted Date: June 2nd, 2020

DOI: https://doi.org/10.21203/rs.3.rs-32128/v1

License: @ (i) This work is licensed under a Creative Commons Attribution 4.0 International License. Read Full License 


\section{Abstract}

Background: The obesity rate has increased in South Korea as a result of changing dietary habits and decreasing physical activity. This study aimed to evaluate the relationships between eating rate and obesity.

Methods: Multiple logistic regression analyses were conducted using raw data of the Korean Community Health Survey 2017 for the Gangwon Province and nationwide data to evaluate the relationships between eating rate and obesity.

Results: Among men, the major factor affecting obesity was an eating rate of $\leq 20 \mathrm{~min}$ (odds ratio $=1.17$ $(1.03,1.33) ; P<0.01)$. In case of women, factors affecting obesity were an eating rate of $\leq 20 \mathrm{~min}$ (odds ratio $=1.15(1.02,1.29) ; P<0.05)$, and irregular mealtimes (odds ratio $=1.16(1.03,1.30) ; P<0.05)$.

Conclusion: Implementing simple strategies to improve dietary and lifestyle habits may assist in weight and obesity management. These findings may provide useful strategies for future developing a culture-oriented approach to obesity management.

\section{Introduction}

The population of South Koreans with obesity has grown due to changes in dietary habits and decreasing physical activity. According to the National Health Statistics, the prevalence of obesity (body mass index [BMI] $\geq 25$ ) among adults aged $\geq 19$ years or older was $34.8 \%$ in 2016 , which was higher than that in $2005(31.3 \%)$, suggesting that over one-third of the population was obese. The prevalence of severe obesity (BMI $\geq 30)$ has persistently risen over the last 10 years and is expected to double by 2030 . According to a study that analyzed treatment costs using national health insurance data from 2016, obesity-related illnesses incurred costs of approximately 7.5 billion USD. The comparative study on healthcare service utilization between people with different health behavior types found that the highest costs were associated with obesity, and these costs are consistently trending upward [1]. Accordingly, the World Health Organization has classified obesity as a disease and has highlighted its major role in the development of eight types of cancer, including esophageal, colorectal, and pancreatic cancer [1]. Therefore, obesity is a global health problem.

The United Kingdom and the United States are working to reduce obesity rates by actively pursuing preventative strategies and launching whole-of-government campaigns at the national level, including promoting healthy foods and improving their accessibility, encouraging physical activity and constructing suitable environments for exercise, and providing personalized obesity management for at-risk groups. Although national-level efforts are essential for reducing obesity, regional-level strategies also need to be developed due to cultural factors. In Gangwon Province, South Korea, the physical activity rate is low owing to the mountainous terrain and densely populated residential areas, which are non-conducive environments for walking, and the diet includes calorically dense meals; notably, the obesity rate is gradually increasing in this area. Therefore, a "culture-oriented approach" that fits local lifestyles also should be taken into account.

Obesity is known as result from an imbalance in energy intake and expenditure; therefore, the emphasis has been placed on either reduced food intake or increased physical activity. Consequently, studies have focused on the development of education and programs pertaining to the quality and quantity of foods and exercise 
requirements. However, despite temporarily reduced food intake, the maintenance of a lower-calorie diet is difficult, and compliance is low [2]. Also, physical activity and weight have a complicated relationship, involving numerous factors, the issue of obesity has not been readily resolved despite multiple intervention programs [3]. Therefore, identifying and presenting simple weight-management "strategies" are required instead of emphasizing behavioral changes, such as restricting calorie intake and increasing physical activity.

The physiological studies explored the effect of the satiety signals and calorie intake, and provide evidence that the decreasing of eating rate lead to satiety with lower calorie intake [4-6]. The evidence show that obese individuals are less inclined to chew their food thoroughly and are more likely to eat quickly and take large mouthfuls than those without obesity [7-9], leading to excessive caloric intake, obesity, and an increase in the risk of cardiovascular disease[10]. Eating slowly facilitates satiation by allowing time for the transmission of the satiety signal to the brain, which takes approximately $20 \mathrm{~min}$ [11]. Therefore, at least $20 \mathrm{~min}$ of mastication is needed for the brain to recognize satiety, thereby preventing overeating [7], and plays an important role in behavioral correction for obesity.

Although the impacts of eating rate on health are being increasingly recognized, and population-level improvement strategies are lacking. Guidelines have been proposed for the adolescent populations of certain countries; however, guidelines on dietary habits for adults are required additional development. In this study, we aimed to provide understanding of relationships between eating rate on obesity among adults.

\section{Methods}

\section{Study design}

This cross-sectional study analyzed the relationships between eating rate, sedentary time and obesity in adults. The secondary data from the Community Health Survey (CHS) 2017 was used and 18 cities and counties of Gangwon province were represented [12]. The CHS was launched in 2008 under Article 4 of the Regional Public Health Act and has been conducted every year as a basis for community health projects. The study design was complex: samples were first stratified based on district (Dong/Eup/Myeon) subunits and types of residence (e.g., apartment or house) and classified by proportional block/settlement (Tong/Ban/Ri) sizes. Sample households were then selected by systematic sampling, and trained interviewers visited each chosen home to interview adult household members aged 19 years or older using computer workstations [13].

To define obesity based on BMI, we analyzed participants aged 19 years or older who self-reported their height and weight. The prevalence of underweight adults was $3.9 \%$, which was lower than the prevalence of the obese population. However, because being underweight presents other health risks owing to a lack of nutrients, underweight participants were excluded from this study.

\section{Study variables}

Participants with $\mathrm{BMI} \geq 18.5$ and $<25 \mathrm{~kg} / \mathrm{m}^{2}$ were assigned to the normal weight group, whereas those with $\mathrm{BMI} \geq 25 \mathrm{~kg} / \mathrm{m}^{2}$ were assigned to the obesity group. The dependent variable was obesity status. The independent variables included sedentary time during leisure periods on weekdays and weekends and dietary 
habits, such as eating rate (derived from the amount of time one spends eating one meal) and mealtime regularity. Information on dietary habits was collected only in Gangwon Province using additional questions. The eating rate was evaluated based on the following question, "how many minutes do you typically spend eating meals?" The question, "in the last week, did you typically eat meals at regular set times?", was used to evaluate mealtime regularity. We categorized the eating rate into the following two groups: fast (those who took $\leq 20 \mathrm{~min}$ to eat one meal) and normal (those who took $>21 \mathrm{~min}$ to eat one meal). Mealtime regularity was categorized into regular and irregular groups.

Certain variables for physical activity were used as adjustment variables, including moderate-to-intense physical activity ( $\geq 20 \mathrm{~min} /$ day of intense physical activity for $\geq 3$ days, or $\geq 30 \mathrm{~min} /$ day of moderate physical activity in $\geq 5$ days in the last week), walking ( $\geq 30 \mathrm{~min} /$ day for $\geq 5$ days in the previous week), and the locally selected questions of regular exercise (regularly performing exercise during the last month). The sociodemographic variables included gender (male and female), age group (20-29, 30-39, 40-49, 50-59, 60-69, and 70+ years), occupation (professional or administrative, office, sales or service, agriculture, forestry, fishery, technical and simple labor, homemaking, and others), education (uneducated, elementary school, middle school, high school, and university and higher education), and marital status (married, unmarried, and others). After data cleaning and excluding participants with missing data, 7,311 men and 8,522 women were included in the analyses.

\section{Statistical analysis}

For data analysis, participants were stratified by gender (male and female). Descriptive statistics and chisquare tests were used to evaluate the relationships between obesity, eating rate, and mealtime regularity. Multiple logistic regression analyses were performed to investigate the relationships between several factors simultaneously. Because obesity (the dependent variable) was a dichotomous variable, its odds ratios (ORs) were analyzed based on the adjustment and independent variables during regression analysis. The independent variables were sedentary time, eating rate, and mealtime regularity, and physical activity and sociodemographic variables were used as adjustment variables. IBM SPSS Statistics (Ver. 24.0) and SAS (Ver. 9.4) software were used for data analysis.

\section{Ethics statement}

The study was approved by the K University Institutional Review Board (K***IRB-2019-11-007) and was conducted using secondary data from CHS. Accordingly, informed consent was not required.

\section{Results}

\section{General characteristics of participants}

The social-demographic characteristics of the study participants were diverse. In the case of gender, women participants were slightly predominant (men, 46.2\%; women, 53.8\%). Prevalent age group was the older adults age 70 years and older (24.7\%), followed by the 50 s group (22.1\%) and 60 s group (20.2\%). Distribution of the participants in age group 20s, 30s, and 40s was followed as $6.8 \%, 10.4 \%$, and $15.7 \%$ respectively. In case of 
occupations, $21.1 \%$ was employed in technical or simple labor works, $18.4 \%$ was homemaking, $18.3 \%$ were in the other group, $14.4 \%$ represented sales and services workers, $13.8 \%$ were employed in agriculture, forestry, or fishery, $7 \%$ were professional or administrative workers, and $6.9 \%$ were office workers. Thirty-two-point-three percent of participants graduated high school, $23 \%$ had university or higher education, $18.6 \%$ graduated elementary school, $13.2 \%$ finished middle school, and $12.9 \%$ were uneducated. Most of the participants were married $(71.1 \%)$, only $10.7 \%$ were unmarried, and the rest of the participants were divorced, bereaved or separated (18.2\%).

\section{Relationship between obesity and lifestyle habits by gender}

Distribution of the participants with normal weight and obesity presented in Table 1. The relationships between obesity and the independent variables, including walking, moderate-to-intense physical activity, and eating rate showed significant differences among men $(P<0.05)$. In the case of the women, regular exercise and eating rate were significantly different $(P<0.05)$. The present of the participants with obesity were prevalence among man who reported no walking, but performed moderate-to-intense physical activities, and had faster eating rate $(37.4 \%, 39.4 \%$, and $37.4 \%$ respectively). The percentage of obese women was higher among those who performed regular exercise $(30.9 \%)$ and has a faster eating rate $(31.1 \%)$. 
Table 1

Bivariate analysis of the independent variables with obesity

\begin{tabular}{|c|c|c|c|c|c|c|c|}
\hline \multicolumn{8}{|l|}{ (unit: N(\%)) } \\
\hline \multirow[t]{2}{*}{ Variables } & & \multicolumn{2}{|l|}{ Males } & \multicolumn{3}{|c|}{ Females } & \multirow[b]{2}{*}{ Chi-square } \\
\hline & & $\begin{array}{l}\text { Normal } \\
\text { weight }\end{array}$ & Obesity & Chi-square & $\begin{array}{l}\text { Normal } \\
\text { weight }\end{array}$ & Obesity & \\
\hline \multirow{2}{*}{\multicolumn{2}{|c|}{ Total }} & 4448 & 2559 & & 5303 & 2263 & \\
\hline & & (63.5\%) & $(36.5 \%)$ & & $(70.1 \%)$ & (29.9\%) & \\
\hline \multirow[t]{12}{*}{ Age } & \multirow[t]{2}{*}{$20 \mathrm{~s}$} & 323 & 184 & \multirow[t]{12}{*}{$206.716^{\star \star \star}$} & 375 & 97 & $87.91^{\star \star \star}$ \\
\hline & & (63.7\%) & $(36.3 \%)$ & & $(79.4 \%)$ & $(20.6 \%)$ & \\
\hline & \multirow[t]{2}{*}{$30 \mathrm{~s}$} & 381 & 397 & & 583 & 173 & \\
\hline & & $(49.0 \%)$ & $(51.0 \%)$ & & $(77.1 \%)$ & $(22.9 \%)$ & \\
\hline & \multirow[t]{2}{*}{$40 \mathrm{~s}$} & 662 & 529 & & 861 & 321 & \\
\hline & & $(55.6 \%)$ & $(44.4 \%)$ & & $(72.8 \%)$ & $(27.2 \%)$ & \\
\hline & \multirow[t]{2}{*}{$50 \mathrm{~s}$} & 1015 & 598 & & 1263 & 529 & \\
\hline & & $(62.9 \%)$ & $(37.1 \%)$ & & $(70.5 \%)$ & $(29.5 \%)$ & \\
\hline & \multirow[t]{2}{*}{$60 s$} & 948 & 500 & & 1017 & 612 & \\
\hline & & $(65.5 \%)$ & $(34.5 \%)$ & & $(62.4 \%)$ & $(37.6 \%)$ & \\
\hline & \multirow[t]{2}{*}{$\geq 70$ s } & 1119 & 351 & & 1204 & 531 & \\
\hline & & (76.1\%) & $(23.9 \%)$ & & $(69.4 \%)$ & $(30.6 \%)$ & \\
\hline \multirow[t]{12}{*}{ Occupation } & \multirow{2}{*}{$\begin{array}{l}\text { Professional/ } \\
\text { administrative }\end{array}$} & 300 & 235 & \multirow[t]{12}{*}{ 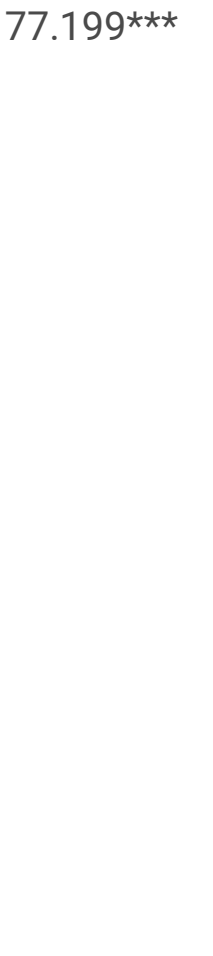 } & 428 & 96 & $69.656^{\star \star *}$ \\
\hline & & (56.1\%) & $(43.9 \%)$ & & $(81.7 \%)$ & $(18.3 \%)$ & \\
\hline & \multirow[t]{2}{*}{ Office work } & 294 & 260 & & 380 & 103 & \\
\hline & & (53.1\%) & $(46.9 \%)$ & & $(78.7 \%)$ & $(21.3 \%)$ & \\
\hline & \multirow{2}{*}{$\begin{array}{l}\text { Sales and } \\
\text { services }\end{array}$} & 440 & 298 & & 1029 & 409 & \\
\hline & & (59.6\%) & $(40.4 \%)$ & & $(71.6 \%)$ & $(28.4 \%)$ & \\
\hline & \multirow{2}{*}{$\begin{array}{l}\text { Agriculture, } \\
\text { forestry, and } \\
\text { fishery }\end{array}$} & 873 & 410 & & 490 & 262 & \\
\hline & & $(68.0 \%)$ & $(32.0 \%)$ & & $(65.2 \%)$ & $(34.8 \%)$ & \\
\hline & \multirow{2}{*}{$\begin{array}{l}\text { Technical/simple } \\
\text { labor }\end{array}$} & 1215 & 743 & & 804 & 378 & \\
\hline & & $(62.1 \%)$ & $(37.9 \%)$ & & $(68.0 \%)$ & $(32.0 \%)$ & \\
\hline & \multirow[t]{2}{*}{ Homemaking } & 2 & 0 & & 1752 & 832 & \\
\hline & & (100.0\%) & $(0.0 \%)$ & & $(67.8 \%)$ & $(32.2 \%)$ & \\
\hline
\end{tabular}




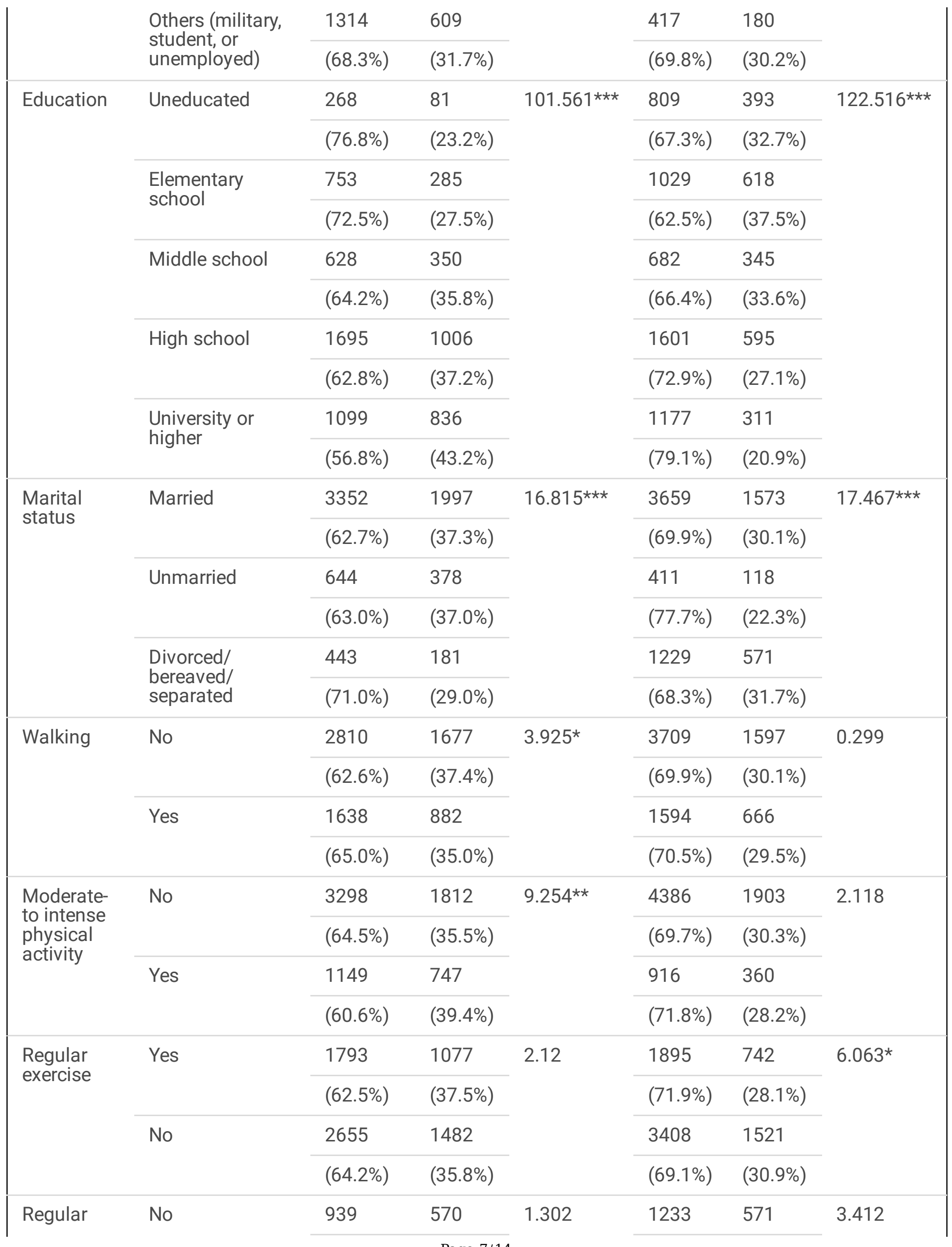




\begin{tabular}{|c|c|c|c|c|c|c|c|}
\hline \multirow[t]{3}{*}{ meals } & & (62.2\%) & (37.8\%) & & (68.3\%) & (31.7\%) & \\
\hline & \multirow[t]{2}{*}{ Yes } & 3509 & 1989 & & 4069 & 1692 & \\
\hline & & (63.8\%) & $(36.2 \%)$ & & (70.6\%) & $(29.4 \%)$ & \\
\hline \multirow[t]{4}{*}{ Eating rate } & \multirow[t]{2}{*}{$\leq 20$ minutes } & 3493 & 2090 & \multirow[t]{4}{*}{$9.801^{* *}$} & 3813 & 1720 & \multirow[t]{4}{*}{$13.586^{\star \star \star *}$} \\
\hline & & $(62.6 \%)$ & $(37.4 \%)$ & & $(68.9 \%)$ & $(31.1 \%)$ & \\
\hline & \multirow[t]{2}{*}{$\geq 21$ minutes } & 954 & 469 & & 1490 & 543 & \\
\hline & & $(67.0 \%)$ & $(33.0 \%)$ & & (73.3\%) & $(26.7 \%)$ & \\
\hline
\end{tabular}

The obesity rate was significantly different in all social-demographic variables for both genders $(P<0.001)$. The percentage of obese men was prevalent in the 30 s age group (51\%), employed in the office (46.9\%), with university or higher degree (43.2\%), and married (37.3\%). While the women aged the 60 s, worked in agriculture, forestry, or fishery field (34.8\%), with elementary education level, and were divorced, bereaved, or separated $(31.7 \%)$ shows a higher percentage of the obesity prevalence.

After stratifying participants by gender, we performed multiple logistic regression analyses to find out relationships between obesity, eating rate, mealtime regularity, and sedentary behavior. The results of multiple logistic regression presented in Table 2. In male participants, after adjusting, eating rate was significantly associated with the development of obesity. Compared with a normal eating rate, a fast eating rate was significantly associated with a higher rate of obesity in men $(O R=1.17 ; P<0.01)$. In female participants, eating rate had statistically significant associations with the development of obesity. The obesity rates were higher in the fast-eating rate group than in the normal eating rate group $(\mathrm{OR}=1.15, P<0.05)$, and in those with irregular mealtimes than in those with regular mealtimes $(\mathrm{OR}=1.16, P<0.05)$. However, the relationship between the obesity rate and physical activities was not found. Despite the social-demographic factors were not our target variables, age, education, and married status have a significant relationship with obesity among man. In the case of women, age, education, occupation significantly influenced on obesity. 
Table 2

Multiple logistic regression analyses for obesity in male and female participants

\begin{tabular}{|c|c|c|c|c|c|}
\hline \multirow[t]{3}{*}{ Variables (tref) } & & \multicolumn{4}{|c|}{$\begin{array}{l}\text { Obesity (compared with normal } \\
\text { weight) }\end{array}$} \\
\hline & & \multicolumn{2}{|l|}{ Males } & \multicolumn{2}{|c|}{ Females } \\
\hline & & OR & $\begin{array}{l}(95 \% \\
\mathrm{Cl})\end{array}$ & OR & $\begin{array}{l}(95 \% \\
\text { Cl) }\end{array}$ \\
\hline \multirow[t]{5}{*}{ Age (20s) } & $30 \mathrm{~s}$ & $1.45^{\star *}$ & $\begin{array}{l}(1.12, \\
1.87)\end{array}$ & 1.27 & $\begin{array}{l}(0.90, \\
1.79)^{\prime}\end{array}$ \\
\hline & $40 \mathrm{~s}$ & 1.07 & $\begin{array}{l}(0.83, \\
1.38)\end{array}$ & $1.51 *$ & $\begin{array}{l}(1.08, \\
2.12)\end{array}$ \\
\hline & $50 \mathrm{~s}$ & 0.78 & $\begin{array}{l}(0.60, \\
1.01)\end{array}$ & 1.32 & $\begin{array}{l}(0.94, \\
1.86)\end{array}$ \\
\hline & $60 s$ & $0.72 *$ & $\begin{array}{l}(0.55, \\
0.95)\end{array}$ & $1.56 *$ & $\begin{array}{l}(1.09, \\
2.22)\end{array}$ \\
\hline & $\geq 70 \mathrm{~s}$ & $0.47^{* \star *}$ & $\begin{array}{l}(0.35, \\
0.62)\end{array}$ & 1.06 & $\begin{array}{l}(0.74, \\
1.54)^{\prime}\end{array}$ \\
\hline \multirow{6}{*}{$\begin{array}{l}\text { Occupation } \\
\text { (professional/ administrative) }\end{array}$} & Office work & 1.07 & $\begin{array}{l}(0.84 \\
1.36)\end{array}$ & 1.13 & $\begin{array}{l}(0.82, \\
1.54)^{\prime}\end{array}$ \\
\hline & Sales and services & 0.90 & $\begin{array}{l}(0.72, \\
1.14)\end{array}$ & 1.29 & $\begin{array}{l}(0.98, \\
1.69)\end{array}$ \\
\hline & $\begin{array}{l}\text { Agriculture, forestry, and } \\
\text { fishery }\end{array}$ & 0.86 & $\begin{array}{l}(0.68, \\
1.08)\end{array}$ & $1.43^{*}$ & $\begin{array}{l}(1.06, \\
1.93)\end{array}$ \\
\hline & Technical/simple labor & 0.90 & $\begin{array}{l}(0.73, \\
1.10)\end{array}$ & $1.36 *$ & $\begin{array}{l}(1.02, \\
1.80)\end{array}$ \\
\hline & Homemaking & . & & $1.53^{* \star}$ & $\begin{array}{l}(1.17, \\
1.98)\end{array}$ \\
\hline & Others & 0.86 & $\begin{array}{l}(0.69, \\
1.07)\end{array}$ & $1.55^{\star \star}$ & $\begin{array}{l}(1.13, \\
2.13)\end{array}$ \\
\hline \multirow{4}{*}{$\begin{array}{l}\text { Education } \\
\text { (uneducated) }\end{array}$} & Elementary school & 1.06 & $\begin{array}{l}(0.80, \\
1.42)\end{array}$ & 1.09 & $\begin{array}{l}(0.94, \\
1.32)\end{array}$ \\
\hline & Middle school & $1.36 *$ & $\begin{array}{l}(1.02, \\
1.83)\end{array}$ & 0.89 & $\begin{array}{l}(0.74, \\
1.11)^{\prime}\end{array}$ \\
\hline & High school & 1.18 & $\begin{array}{l}(0.89, \\
1.57)\end{array}$ & $0.69 * * *$ & $\begin{array}{l}(0.57, \\
0.87)\end{array}$ \\
\hline & University or higher & 1.24 & $\begin{array}{l}(0.92, \\
1.67)\end{array}$ & $0.56 * * *$ & $\begin{array}{l}(0.44, \\
0.73)\end{array}$ \\
\hline \multirow{2}{*}{$\begin{array}{l}\text { Marital status } \\
\text { (married) }\end{array}$} & Unmarried & $0.69 * \star \star$ & $\begin{array}{l}(0.58, \\
0.83)\end{array}$ & 1.02 & $\begin{array}{l}(0.75, \\
1.37)\end{array}$ \\
\hline & Divorced/bereaved/separated & $0.78^{* *}$ & $\begin{array}{l}(0.65, \\
0.94)\end{array}$ & 0.96 & $\begin{array}{l}(0.84, \\
1.10)\end{array}$ \\
\hline
\end{tabular}




\begin{tabular}{|c|c|c|c|c|c|}
\hline Walking (yes) & No & 1.11 & $\begin{array}{l}(0.99 \\
1.23)\end{array}$ & 1.01 & $\begin{array}{l}(0.90 \\
1.14)^{\prime}\end{array}$ \\
\hline $\begin{array}{l}\text { Moderate-to intense physical } \\
\text { activity (yes) }\end{array}$ & No & 0.92 & $\begin{array}{l}(0.81 \\
1.03)\end{array}$ & 1.08 & $\begin{array}{l}(0.94, \\
1.24)^{\prime}\end{array}$ \\
\hline Regular exercise (yes) & No & 0.93 & $\begin{array}{l}(0.83, \\
1.03)\end{array}$ & 1.09 & $\begin{array}{l}(0.97 \\
1.22)^{\prime}\end{array}$ \\
\hline Regular meals (yes) & No & 1.01 & $\begin{array}{l}(0.89, \\
1.15)\end{array}$ & $1.16 *$ & $\begin{array}{l}(1.03, \\
1.30)\end{array}$ \\
\hline $\begin{array}{l}\text { Eating rate } \\
\text { ( } \geq 21 \text { minutes) }\end{array}$ & $\leq 20$ minutes & $1.17^{* *}$ & $\begin{array}{l}(1.03, \\
1.33)\end{array}$ & $1.15^{\star}$ & $\begin{array}{l}(1.02, \\
1.29)\end{array}$ \\
\hline
\end{tabular}

\section{Discussion}

Obesity studies have mainly focused on weight loss methods, either by reducing food intake or increasing physical activity. However, bodyweight needs to be controlled throughout one's lifetime, not only in the shortterm. Therefore, it is essential that weight control goals include both weight loss and weight maintenance. It is also necessary to change perspectives related to obesity, and strategies are needed to alter behaviors by changing individual perceptions. In South Korea, health promotion indices are the lowest in Gangwon Province, and this area had the worst obesity indices in South Korea during the last 5 years [14]. In this study, we examined the relationships between obesity and eating rate to find strategies that could help prevent obesity in real-life settings.

In our study, the obesity rates in Gangwon Province were $36.5 \%$ in men and $29.9 \%$ in women, demonstrating a higher prevalence of obesity in men. After controlling for adjustment variables, male participants with an eating rate of $\leq 20 \mathrm{~min}$ had a higher obesity rate. Among women, the obesity rate was higher in participants with an eating rate of $\leq 20$ min and irregular mealtimes. Regardless of gender, an eating rate of $\leq 20$ min was correlated with obesity. Previous studies also showed similar results $[15,16]$. Regardless, the study did not report a relationship between eating rate and obesity [17]. It is important to highlight that studies on the physiological effect of the eating rate and calorie intake showed a relationship between satiation, satiety and health behavior $[6,18,19]$. Particularly, Andrade et al. [4] reported that the individuals who spend more time for one meal intake are satiety and satisfactory with food intake less weight and calories than the individuals who eat a meal within 20 minutes.

Also, important to mark the fact of the impact of South Korean culture that should not be excluded. The socalled "quickly-quickly" (bballi-bballi) culture permeates every aspect of the South Korean lifestyle, and meals are no exception[20]. Ahn et al. (2007) found that the meal durations of university students with obesity were significantly shorter than those with a healthy weight [21]. In another study of university students of both genders, students in the obese group were found to have a faster eating rate than those in the healthy group[9]. Also, a longitudinal study among Japanese students reported that male student and those who have a faster eating rate in baseline had increased of overweight risk [22]. In addition, it was found that shorter meal durations were associated with BMI, independent of overall energy intake [23]. These findings further indicate the relationship between a fast eating rate and obesity. 
Previous studies on middle-aged obesity showed that obese women had more irregular dietary habits and higher intakes of animal fat than did non-obese women [15, 24], and irregular breakfast habits contributed greatly to obesity [25]. Consistently, in the present study, obese women were more likely than healthy-weight women to eat irregular meals. These findings suggest that irregular meals may promote binge eating, leading to faster eating rates, and are linked to obesity. However, in a study by Sohn and Jin, obesity was not associated with meal regularity or eating three meals per day among women aged 20 years or older [26]. These inconsistent findings suggest that age might be an important factor contributing to obesity.

Programs and treatments for weight control based on behavioral correction require extensive time. However, many individuals desire to reduce weight within a short time [27]. Adjusting personal dietary habits does not produce rapid weight loss, although lifestyle habits for obesity management play an essential role in obesity prevention and control [28]. Notably, previous studies emphasized the need to increase non-exercise activity thermogenesis (NEAT) rather than exercise [29]. For instance, a study comparing energy expenditure between obese and non-obese groups found lower NEAT due to sedentary behavior, resulting in reduced overall energy expenditure, in the obese group [30]. This observation supports our findings that introducing simple habits into daily life may impact obesity.

Despite that our study does not aim to explore the influence of the social-demographic factors on the obesity rate, our findings contributed to previous studies were age, education level, occupation, and marital status were significant factors [31-33]. Middle age men were more predisposed to obesity rather than older adults, while women developed obesity with increasing age [33]. The prevalence of obesity was higher among women who involved in unskilled work rather than the professional workers. However, this patent closely related to the level of education, and women with higher education might have more access and knowledge about the healthy lifestyle [34]. Marital status was significant factors to develop obesity among the married men, that is similar to the previous studies [35, 36].

This study has several limitations. First, the study was designed as cross-sectional, so causal relationships between obesity and dietary behavior were not evaluated. Second limitation is that we could not measure the participants' actual heights and weights or confirm their precise meal as data was self-reported based. Despite these limitations, the CHS provides large-scale research data at the local government level in South Korea using representative samples. Therefore, the relationships observed between obesity and eating rate are valid. The factors affecting obesity are considerably complex, and further studies are needed to elucidate the personal behaviors implicated in this study, as well as a longitudinal study is necessary to perform to evaluated continues effect of the eating rate on the obesity development. Notably, this study provided valuable data and findings by including multiple factors that could be used to distinguish between individual eating rate and physical activity. Therefore, the present findings will contribute to planning future obesity management programs. Weight control requires persistent behavioral changes and motivation, and obesity programs taking these factors into consideration need to be developed in the future.

\section{Conclusion}

We examined the relationships between eating rate during leisure periods and obesity to provide evidence for obesity prevention strategies. The primary factor affecting obesity among male and female participants was 
an eating rate of $\leq 20$ min; additionally, irregular meals were significant factors to develop obesity among female participants. These findings strongly suggest that obesity could be prevented by simple changes in dietary and lifestyle habits. Based on these findings, behavioral correction strategies adjusting for eating rate should be introduced to improve the impact of community-based obesity prevention and management programs. The findings in this study could be used to establish strategies for obesity prevention programs by modifying lifestyle habits. Further studies with more extensive and diverse cohorts are needed to validate our findings.

\section{Declarations}

Ethics approval and consent to participate: The study was approved by the K University Institutional Review Board (K***|RB-2019-11-007) and was conducted using secondary data from CHS. Accordingly, informed consent was not required.

Consent for publication: Not applicable

Availability of data and materials: The data that support the findings of this study are available from Korean Center for Disease Control and Prevention but restrictions apply to the availability of these data, which were used under license for the current study, and so are not publicly available. Data are however available from the authors upon reasonable request and with permission of Korean Center for Disease Control and Prevention.

Competing interests: The authors have no potential conflicts of interest to disclose.

Funding: This work was supported by the Research Program funded by the Korea Centers for Disease Control and Prevention (fund code \#2019P330500)

Authors' contributions: JHS prepared research conception and design. Data acquisition, analysis and interpretation, and manuscript drafting were prepared by JHS, JSM. Statistical analysis was performed by JSM. JHS and DY did critical revision and finalization of the manuscript. All authors read and approved the final manuscript.

Acknowledgements: Not applicable

\section{References}

1. Lee S. Analysis of the impact of health behavior on health insurance. The 1st Medical Public BIG DATA Research Conference; Seoul, Korea2019.

2. Kim Y-S, Kim S-K, Kim S-Y, Hong I-S, Chang U-J. The Effect of Nutrition Education and the Diet Rice Bowl on Weight Control. Journal of the Korean Dietetic Association. 2013;19(3):287-97

3. Tan AK, Dunn RA, Samad MIA, Feisul MI. Sociodemographic and health-lifestyle determinants of obesity risks in Malaysia. Asia Pacific Journal of Public Health. 2011;23(2):192-202

4. Andrade AM, Greene GW, Melanson KJ. Eating slowly led to decreases in energy intake within meals in healthy women. Journal of the American Dietetic Association. 2008;108(7):1186-91 
5. Kokkinos A, le Roux CW, Alexiadou K, Tentolouris N, Vincent RP, Kyriaki D, et al. Eating slowly increases the postprandial response of the anorexigenic gut hormones, peptide $Y Y$ and glucagon-like peptide-1. The Journal of Clinical Endocrinology \& Metabolism. 2010;95(1):333-7

6. Benelam B. Satiation, satiety and their effects on eating behaviour. Nutrition bulletin. 2009;34(2):126-73

7. Ookuma K, Yoshimatsu H, Sakata T, Adachi K. The effect of chewing chart recording in the treatment of obesity. Jpn J Psychosom Med. 2000;40:247-53

8. Jo H-S, Lee B-Y. Evaluation of Obesity Clinic Program in Public Community Health Centers in South Korea. Asia Pacific Journal of Public Health. 2013;25(4):335-44

9. Jun S-C, Kim Y-J, Kim Y-S, Kim S-K, Kim D-G, Chang U-J. The relationships of chewing frequency, eating rates, and food consumption with the body mass index and gender of college students. Journal of the Korean Dietetic Association. 2013;19(2):103-11

10. Kim DH. Eating fast leads to hyperlipidemia and obesity 2012 [cited 2019 September 24]. Available from: http://news.kmib.co.kr/article/view.asp?arcid=0006382555.

11. Lee Y. A study on the eating behavior, nutritional status and health condition of obese adult attending a weight control exercise. Korean J Food \& Nutr. 2000;13(2):125-32

12. Community Health Survey. Korea Centers for Disease Control and Prevention; 20172017.

13. Kim M, Oh G-J, Lee Y-H. Gender-specific factors associated with suicide attempts among the communitydwelling general population with suicidal ideation: the 2013 Korean community health survey. Journal of Korean medical science. 2016;31(12):2010-9

14. 2008-2018 Community Health Statistics at a glance. Korea Centers for Disease Control and Prevention; 2018.

15. Leong SL, Madden C, Gray A, Waters D, Horwath C. Faster self-reported speed of eating is related to higher body mass index in a nationwide survey of middle-aged women. Journal of the American Dietetic Association. 2011;111(8):1192-7

16. Lee K, Kim D-H, Jang J, Nam G, Shin Y, Bok A, et al. Eating rate is associated with cardiometabolic risk factors in Korean adults. Nutrition, Metabolism and Cardiovascular Diseases. 2013;23(7):635-41

17. Paz-Graniel I, Babio N, Mendez I, Salas-Salvadó J. Association between eating speed and classical cardiovascular risk factors: a cross-sectional study. Nutrients. 2019;11(1):83

18. Maljaars J, Peters $\mathrm{H}$, Masclee A. The gastrointestinal tract: neuroendocrine regulation of satiety and food intake. Alimentary pharmacology \& therapeutics. 2007;26:241-50

19. Ohkuma T, Hirakawa Y, Nakamura U, Kiyohara Y, Kitazono T, Ninomiya T. Association between eating rate and obesity: a systematic review and meta-analysis. International journal of obesity. 2015;39(11):1589-96

20. Kang J-M. The cultural politics of'ppallippalli': A study on the'speed communication'in korea. Journal of Communication Science. 2010;10(3):47-80

21. Ahn M-S, Chang I-Y, Kim K-H. Comparisons of UCP2 polymorphism, dietary habits, and obesity index in normal and obese university students. Journal of the Korean Society of Food Culture. 2007;22(4):404-13

22. Yamane M, Ekuni D, Mizutani S, Kataoka K, Sakumoto-Kataoka M, Kawabata Y, et al. Relationships between eating quickly and weight gain in $\mathrm{J}$ apanese university students: A longitudinal study. Obesity. 2014;22(10):2262-6 
23. Kamath S, D'Souza J. Prevalence of obesity among the medical students: a cross sectional study in a south Indian medical college. Al Ameen J Med Sci. 2013;6(1):93-5

24. Lee SM, Oh AR, Ahn HS. Major dietary patterns and their associations with socio-demographic, psychological and physical factors among generally healthy Korean middle-aged women. Korean J Community Nutr. 2008;13(3):439

25. Kim H-K, Kim M-J. Effects of weight control program on dietary habits and blood composition in obese middle-aged women. Korean Journal of Nutrition. 2010;43(3):273-84

26. Sohn A-R, Jin K-Y. The difference of socio-demographic variables and health-related behaviors among groups of body mass index. Korean journal of health education and promotion. 2008;25(4):1-11

27. Choi JM, Kim C-B. Obesity management and scientific evidence. Journal of the Korean Medical Association/Taehan Uisa Hyophoe Chi. 2011;54(3)

28. Phillips CM, Dillon C, Harrington JM, McCarthy VJ, Kearney PM, Fitzgerald AP, et al. Defining metabolically healthy obesity: role of dietary and lifestyle factors. PloS one. 2013;8(10)

29. Healy GN, Dunstan DW, Salmon J, Cerin E, Shaw JE, Zimmet PZ, et al. Objectively measured light-intensity physical activity is independently associated with 2-h plasma glucose. Diabetes care. 2007;30(6):1384-9

30. Levine JA, Lanningham-Foster LM, McCrady SK, Krizan AC, Olson LR, Kane PH, et al. Interindividual variation in posture allocation: possible role in human obesity. Science. 2005;307(5709):584-6

31. Malik VS, Willett WC, Hu FB. Global obesity: trends, risk factors and policy implications. Nature Reviews Endocrinology. 2013;9(1):13

32. Molarius A. The contribution of lifestyle factors to socioeconomic differences in obesity in men and women-a population-based study in Sweden. European Journal of Epidemiology. 2003;18(3):227-9

33. Sobal J. Social and cultural influences on obesity. International textbook of obesity. 2001:305-22

34. Aekplakorn W, Inthawong R, Kessomboon P, Sangthong R, Chariyalertsak S, Putwatana P, et al. Prevalence and trends of obesity and association with socioeconomic status in Thai adults: national health examination surveys, 1991-2009. Journal of Obesity. 2014;2014

35. Harcourt KA, Appleton J, Clegg ME, Hunter L. The influence of social relationships on men's weight. Journal of Nutrition Education and Behavior. 2020;52(2):106-13

36. Sobal J, Rauschenbach BS, Frongillo Jr EA. Marital status, fatness and obesity. Social science \& medicine. 1992;35(7):915-23 